\title{
Prehypertension should be considered a special blood pressure phase
}

\author{
Hypertension Research (2012) 35, 561-562; doi:10.1038/hr.2012.31; published online 8 March 2012
}

According to JNC-7, ${ }^{1}$ blood pressure is categorized into normotension $(<120$ per $80 \mathrm{~mm} \mathrm{Hg})$, prehypertension (120-139 and/ or $80-89 \mathrm{~mm} \mathrm{Hg})$ and hypertension $(\geqslant 140$ per $90 \mathrm{~mm} \mathrm{Hg})$. There is a general consensus on the diagnosis and treatment of hypertension. ${ }^{1,2}$ However, there are controversies about prehypertension involving the term itself and the appropriate pharmacological interventions. ${ }^{2,3}$ Our data suggest that prehypertension should be considered a special blood pressure phase, supporting the use of the term 'prehypertension' and early interventions.

In 2007, there was a re-examination of 711 individuals who had been examined in 1992 for cardiovascular diseases (CVD) risk factors according to the MONICA protocol in an urban community located in Chengdu, China. As 114 of these individuals had hypertension in 1992, they were excluded from the analysis. Therefore, the complete data set for 597 individuals was available for analysis. The detailed information for these individuals has been reported elsewhere. ${ }^{4,5}$

The re-examination was approved by the West China Hospital of Sichuan University. All participants provided written informed consent. Normotension, prehypertension and hypertension were defined according to JNC-7. ${ }^{1}$ Comparisons between groups were performed with an independent $t$ test for normally distributed variables and with the nonparametric Mann-Whitney test for skewed variables. Interactions between categorical variables were evaluated with the Pearson $\chi^{2}$ test. Cox proportional hazards models were used to estimate the hazard ratios (HRs) of incident hypertension associated with prehypertension. Statistical significance was defined as $P<0.05$.

In 1992, the levels of CVD risk factors were higher in the prehypertension group than in the normotension group. These factors include age, systolic blood pressure (SBP), diastolic blood pressure (DBP), total cholesterol (TC), low-density lipoprotein cholesterol (LDL-C), triglyceride (TG), waist circumference and body mass index (BMI; all $P$-values $<0.05$ ). The prevalence of CVD was similar between the two groups ( 1.7 vs. $0.5 \%, P=0.468$ ). In 2007, the cumulative 15-year hypertension incidence was much higher in the initial prehypertension group than in the group of initial normotension ( 91.2 vs. $22.2 \%, P<0.001$ ), and the levels of CVD risk factors, such as age, SBP, DBP, fasting plasma glucose and waist circumference, were higher in the initial prehypertension group than in the initial normotension group (all $P$-values $<0.05$ ). The prevalence of CVD tended to be higher in the initial prehypertension group than in the initial normotension group ( 6.6 vs. $3.1 \%, P=0.052)$. After adjusting for age, sex, waist circumference, BMI, smoking, TC, LDL-C, TG, antihypertensive and antilipidemic medication, prehypertension could statistically predict future hypertension (HR: 5.354, 95\% CI: 4.0947.002, $P<0.001)$.

We think that prehypertension should be considered a distinct blood pressure phase, and our data support the term 'prehypertension' and early interventions. The presence of hypertension was supported by two of our findings. First, the cumulative 15-year hypertension incidence increased sharply in the initial prehypertension group (91.2\%), and the adjusted HR was 5.354. Second, the initial prehypertension group always had higher levels of CVD risk factors.

During the follow-up, the cumulative 15year hypertension incidence was $>90.0 \%$ in the initial prehypertension group. The hypertension incidence increased at an annual rate of $6.0 \%$ in the initial prehypertension group, and other studies revealed similar results. 6,7 The initial prehypertension group always had higher levels of CVD risk factors than the initial normotension group, and others' stu- dies also showed that the prehypertension group had higher levels of CVD risk factors. ${ }^{3}$ These current data suggested that prehypertension is a discrete phase between normotension and hypertension with the special characteristics of a rapid progression to hypertension and the clustering of CVD risk factors. These special prehypertension characteristics should increase the risk of developing CVD. Our study showed that the cumulative prevalence of CVD tended to be higher in the initial prehypertension group than in the initial normotension group during the follow-up (6.6 vs. $3.1 \%, P=0.052$ ), and many studies have shown that prehypertension is associated with CVD. ${ }^{3}$ Individuals with prehypertension should receive early interventions to prevent the progression to hypertension and interrelated CVD. Lifestyle modifications have been recommended for individuals with prehypertension. ${ }^{1}$ However, pharmacological interventions have yielded disparate results, ${ }^{3}$ and more trials are needed.

For the relatively small sample, the present study might have limited statistical power, but the results might provide some information about the blood pressure classification. On the basis of only two examinations, we think that the initial prehypertension group always had high levels of CVD risk factorsbut these levels might be acceptable.

In summary, we propose that prehypertension be considered a distinct blood pressure phase that can quickly progress to hypertension and that is associated with the clustering of CVD risk factors. In addition, our data support the term 'prehypertension' and early interventions. Because of these characteristics, the term 'prehypertension' should be emphasized when treating individuals whose blood pressure places them in this category; this might encourage them to make lifestyle changes to prevent or delay the progression to hypertension and the development of interrelated CVD. 


\section{CONFLICT OF INTEREST}

The authors declare no conflict of interest.

\section{ACKNOWLEDGEMENTS}

This study was supported by a project of the National Eighth Five-Year Research Plan, China (grant no. 85-915-01-02) and by Mega-projects of Science Research for the 11th Five-Year Plan, China (grant no. 2006BAI01A01).

\section{Sen He and Xiaoping Chen}

Department of Cardiovascular Medicine, West China Hospital, Sichuan University,

Chengdu, China

E-mail: happensky@163.com

1 Chobanian AV, Bakris GL, Black HR, Cushman WC, Green LA, Izzo Jr JL, Jones DW, Materson BJ, Oparil S, Wright Jr JT, Roccella EJ. Joint National Committee on
Prevention, Detection, Evaluation, and Treatment of High Blood Pressure; National Heart, Lung, and Blood Institute; National High Blood Pressure Education Program Coordinating Committee. Seventh report of the Joint National Committee on Prevention, Detection, Evaluation, and Treatment of High Blood Pressure. Hypertension 2003; 42: 1206-1252.

2 Mancia G, De Backer G, Dominiczak A, Cifkova R, Fagard R, Germano G, Grassi G, Heagerty AM, Kjeldsen SE, Laurent S, Narkiewicz K, Ruilope L, Rynkiewicz A, Schmieder RE, Struijker Boudier HA, Zanchetti A, Vahanian A, Camm J, De Caterina R, Dean V, Dickstein K, Filippatos G, Funck-Brentano C, Hellemans I, Kristensen SD, McGregor K, Sechtem U, Silber S, Tendera M, Widimsky P, Zamorano JL, Kjeldsen SE, Erdine S, Narkiewicz K, Kiowski W, Agabiti-Rosei E, Ambrosioni E, Cifkova R, Dominiczak A, Fagard R, Heagerty AM, Laurent S, Lindholm LH, Mancia G, Manolis A, Nilsson PM, Redon J, Schmieder RE, Struijker-Boudier HA, Viigimaa M, Filippatos G, Adamopoulos S, AgabitiRosei E, Ambrosioni E, Bertomeu V, Clement D, Erdine S, Farsang C, Gaita D, Kiowski W, Lip G, Mallion JM, Manolis AJ, Nilsson PM, O'Brien E, Ponikowski P, Redon J, Ruschitzka F, Tamargo J, van Zwieten P, Viigimaa M, Waeber B, Williams B, Zamorano JL. The task force for the management of arterial hypertension of the European Society of Hypertension, the task force for the management of arterial hypertension of the European Society of Cardiology. 2007 Guidelines for the manage- ment of arterial hypertension: the task force for the management of arterial hypertension of the European Society of Hypertension (ESH) and of the European Society of Cardiology (ESC). Eur Heart J 2007; 28: 1462-1536.

3 Pimenta E, Oparil S. Prehypertension: epidemiology, consequences and treatment. Nat Rev Nephrol 2010; 6: 21-30.

4 Liu J, Hong Y, D'Agostino Sr RB, Wu Z, Wang W, Sun J, Wilson PW, Kannel WB, Zhao D. Predictive value for the Chinese population of the Framingham CHD risk assessment tool compared with the Chinese Multi-Provincial Cohort Study. JAMA 2004; 291: 2591-2599.

5 Ren J, Grundy SM, Liu J, Wang W, Wang M, Sun J, Liu J, Li Y, Wu Z, Zhao D. Long-term coronary heart disease risk associated with very-low-density lipoprotein cholesterol in Chinese: the results of a 15-year Chinese MultiProvincial Cohort Study (CMCS). Atherosclerosis 2010; 211: 327-332.

6 Vasan RS, Larson MG, Leip EP, Kannel WB, Levy D. Assessment of frequency of progression to hypertension in non-hypertensive participants in the Framingham Heart Study: a cohort study. Lancet 2001; 358: 16821686.

7 Liu LK, Peng LN, Chen LK, Hwang SJ, Chiou ST. Prehypertension among middle-aged and elderly people in Taiwan: a five-year follow-up. J Atheroscler Thromb 2010; 17: 189-194. 